\title{
More Transparency Is Needed in the Reporting of Clinical Research Studies
}

W e read with great interest the systematic review published very recently by Asnafi et $\mathrm{al}^{1}$ on the efficacy and safety of the Woven EndoBridge (WEB); (Sequent Medical, Aliso Viejo, California) aneurysm embolization system for the endovascular therapy of intracranial aneurysms. Their literature search was conducted during a fairly similar period to our previously published systematic review (January 1, 2010, to October 1, 2015, versus January 1, 2010, to September 2015, respectively). ${ }^{2}$ Most surprising, the authors included 15 articles while we selected only 7 articles. For 3 of these, the difference is because we selected articles with $>10$ patients, whereas Asnafi et al included studies with at least 5 patients. For the 5 remaining articles, we assume that we applied a more stringent study selection strategy aimed at detecting potential articles with duplicate published cases. Unlike the systematic review by Asnafi et al, we excluded the article by Papagiannaki et al, ${ }^{3}$ in which the authors stated that among their cohort of 85 patients, 22 and 24 (a total of 46 patients, 54.1\%) of the patients also participated in the WEB Clinical Assessment of IntraSaccular Aneurysm Therapy (WEBCAST) study and the French Observatory study, respectively. Our understanding is that Asnafi et al included the article by Pierot et al, ${ }^{4}$ which combined the 2 populations from WEBCAST and the French Observatory study and the article by Papagiannaki et al. Consequently, this meta-analysis is likely to have included the same population twice, which would make the analysis invalid. Similarly, we assume that patients from several other articles selected in the final meta-analysis, like those from Cognard et al, $2015,{ }^{5}$ and Pierot et al, 2012 and 2013, ${ }^{6,7}$ are at great risk of having been included in other articles in the meta-analysis. On this basis, clarifications should be provided by the authors because by definition, a meta-analysis cannot include several articles with overlaps in the selected population. According to the selection criteria of our systematic review, we excluded articles potentially including the same populations.

In other systematic reviews undertaken in the field of interventional neuroradiology, we have been facing the same problem of identifying duplicate published cases because some au-

http://dx.doi.org/10.3174/ajnr.A4982 thors may publish their results in several articles. This emphasizes the need to carefully take into account several factors during the study selection process, such as the names of the authors, the location of participating centers, and the time of patient selection.

We understand that results from the same clinical research study may lead to several publications, for example, when an outcome measure is made available at different time points. However, this can be misleading within the scope of systematic reviews and the implementation of evidence synthesis methods, and may not allow a fair assessment of health technologies. This advocates for more transparency in the process of publication of clinical research studies. In practice, authors should be urged to systematically state in their article when some of their results have been partially or totally reported elsewhere.

Disclosures: Francis Turjman—UNRELATED: Consultancy: Codman, Stryker, Medtronic*; Grants/Grants Pending: Medtronic, Stryker.* *Money paid to the institution.

\section{REFERENCES}

1. Asnafi S, Rouchaud A, Pierot L, et al. Efficacy and safety of the Woven EndoBridge (WEB) device for the treatment of intracranial aneurysms: a systematic review and meta-analysis. AJNR Am J Neuroradiol 2016 Aug 11. [Epub ahead of print] Medline

2. Armoiry X, Turjman F, Hartmann DJ, et al. Endovascular treatment of intracranial aneurysms with the WEB device: a systematic review of clinical outcomes. AJNR Am J Neuroradiol 2016;37:868-72 CrossRef Medline

3. Papagiannaki C, Spelle L, Januel AC, et al. WEB intrasaccular flow disruptor-prospective, multicenter experience in 83 patients with 85 aneurysms. AJNR Am J Neuroradiol 2014;35:2106-11 CrossRef Medline

4. Pierot L, Spelle L, Molyneux A, Byrne J; WEBCAST and French Observatory Investigators. Clinical and anatomical follow-up in patients with aneurysms treated with the WEB device: 1-year follow-up report in the cumulated population of 2 prospective, multicenter series (WEBCAST and French Observatory). Neurosurgery 2016;78:133-41 CrossRef Medline

5. Cognard C, Januel AC. Remnants and recurrences after the use of the WEB intrasaccular device in large-neck bifurcation aneurysms. Neurosurgery 2015;76:522-30; discussion 530 CrossRef Medline

6. Pierot L, Liebig T, Sychra V, et al. Intrasaccular flow-disruption treatment of intracranial aneurysms: preliminary results of a multicenter 
clinical study. AJNR Am J Neuroradiol 2012;33:1232-38 CrossRef Medline

7. Pierot L, Klisch J, Cognard C, et al. Endovascular WEB flow disruption in middle cerebral artery aneurysms: preliminary feasibility, clinical, and anatomical results in a multicenter study. Neurosurgery 2013;73:27-34; discussion 34-35 CrossRef Medline

(1D) X. Armoiry Hospices Civils de Lyon Délégation à la Recherche Clinique et à l'Innovation Cellule Innovation/UMR-CNRS 5510/MATEIS Lyon, France
University of Warwick Warwick Medical School, Division of Health Sciences Coventry, England (D)F. Turjman (1)B. Gory FHU IRIS, Neuroradiologie Interventionnelle Hôpital Neurologique Pierre Wertheimer Hospices Civils de Lyon Lyon, France University of Lyon 1 Lyon, France 